\title{
RESPOSTAS DE GENÓTIPOS DE FEIJOEIRO À SALINIDADE ${ }^{1}$
}

Giovanni de Oliveira Garcia ${ }^{2}$, Aline Azevedo Nazário ${ }^{3}$, Willian Bucker Moraes ${ }^{4}$, Ivo Zution Gonçalves 5 , João Carlos Madalão ${ }^{6}$

\section{RESUMO}

Com objetivo de avaliar e comparar o efeito da salinidade da solução do solo sobre a resposta de genótipos de feijoeiro foi realizado um experimento em delineamento inteiramente casualizado, com 30 genótipos, cultivados por 25 dias em substrato salino, em casa de vegetação, com cinco níveis de salinidade $\left(2,50 ; 5,00 ; 7,50\right.$ e $10,00 \mathrm{dS} \mathrm{m}^{-1}$ e uma testemunha em substrato não salino) e seis repetições. A análise dos dados e a interpretação dos resultados obtidos nos mostram que a salinidade afetou significativamente o crescimento de todos os genótipos estudados, sendo que o genótipo Serrano se destacou em relação aos demais genótipos, por apresentar maiores valores de MSPA, AFT, TCR e RAF. Este genótipo demonstrou maior tolerância ao estresse salino.

Palavras-chave: Phaseolus vulgaris (L.), estresse salino, crescimento

\section{ABSTRACT \\ SELECTION OF BEAN VARIETIES FOR SALINITY TOLERANCE}

In order to evaluate and compare the response of bean plants to the salinity of soil solution, this green house study was done with 30 genotypes grown for 25 days in a saline substrate, with salinity levels of 2.50, 5.00, 7.50 and $10.00 \mathrm{dS} \mathrm{m}^{-1}$ and compared with non-saline substrate. The experiment was installed in a completely randomized plot design with six replications. The results revealed that salinity significantly affected growth of all genotypes, with genotype 'Serrano' having the maximum values of MSPA, AFT, TCR and RAF. This genotype showed highest tolerance to salt stress.

Keywords: Phaseolus vulgaris (L.), Salt stress, Development.

\section{Recebido para publicação em 26/01/2009. Aprovado em 11/01/2010}

1- Artigo extraído do trabalho de Pós-doutorado Junior do primeiro autor.

2- Eng. Agrônomo, D.S., Depto de Eng. Rural CCAUFES, Alegre, ES, giovanni@cca.ufes.br

3- Estudante de Agronomia, Bolsista PIBIC/UFES, CCAUFES, ES.

4- Eng. Agrônomo, Mestrando em Produção Vegetal, CCAUFES/UFES,

5- Eng. Agrônomo, Mestrando em Produção Vegetal, CCAUFES/UFES.

6- Eng. Agrônomo, Mestrando em Produção Vegetal, CCAUFES/UFES. 


\section{INTRODUÇÃO}

Em todo mundo, a crescente demanda por alimentos tem elevado o uso da irrigação. Em regiões semi-áridas, onde o déficit hídrico está presente na maior parte do ano, e a fim de garantir a produção agrícola, torna-se imprescindível o uso da técnica.. No manejo da irrigação, sob condições de clima árido e semi-árido, quando normalmente a água contém sais solúveis, o uso indevido, na ausência de lixiviação, pode provocar a salinização dos solos, reduzir o crescimento e/ou comprometer o desenvolvimento normal das plantas (FAGERIA, 1989).

Nas regiões afetadas por sais, o estresse salino representa um dos mais sérios fatores que limitam o crescimento e a produção das culturas. A resposta das plantas à salinidade é um fenômeno complexo, envolvendo alterações morfológicas e de crescimento, além de processos fisiológicos e bioquímicos (CRAMER et al., 1994). Assim, em ambientes salinos, a sobrevivência das plantas pode exigir processos adaptativos envolvendo a absorção, o transporte e a distribuição de íons nos vários órgãos da planta bem como a compartimentação de nutrientes minerais dentro das células (MUNNS \& TERMAAT, 1986).

O estresse salino induz uma redução progressiva do crescimento das plantas o que pode ser causado pela redução do potencial osmótico e/ou acumulação excessiva deíons, podendoinduziràtoxicidadeiônica, desequilíbrio nutricional ou ambos (AZEVEDO NETO, 1997). Os processos de crescimento são particularmente sensíveis ao efeito dos sais, de forma que a taxa de crescimento e a produção de biomassa são bons critérios para avaliação do grau de estresse, bem como a capacidade da planta em tolerar o estresse salino (LARCHER, 2000).

A maneira como o estresse salino se desenvolve na planta do feijoeiro é bastante complexa, pois afeta praticamente todos os aspectos do crescimento, incluindo modificações anatômicas, morfológicas, fisiológicas e bioquímicas. No entanto, os prejuízos causados dependem de sua duração e sua severidade, e do estádio de desenvolvimento da mesma.

A maioria dos trabalhos encontrados na literatura que relacionam os efeitos causados pela salinidade da solução do solo ou da água de irrigação sobre o desenvolvimento e, ou crescimento do feijoeiro limitam-se a discustir os resultados apenas sob o ponto de vista estatístico, gerando modelos para as condições experimentais sem, contudo, embasar as discussões nos parâmetros fisiológicos que norteiam o crescimento, desenvolvimento e conseqüentemente a produtividade da cultura que dependem das condições ambientais.

Vários conceitos e técnicas de análise de crescimento são encontrados na literatura, para o estudo dos efeitos ambientais sobre o crescimento das plantas. Dessa forma, a interferência do ambiente sobre a produção das culturas pode ser evidenciada pelas alterações no crescimento dos vegetais. A análise de crescimento é um meio prático e preciso para se avaliar o crescimento e inferir sobre a contribuição de diferentes processos fisiológicos no comportamento vegetal (BENINCASSA, 2003).

Diante do exposto, o presente trabalho teve como objetivo selecionar, por meio de uma análise de crescimento, genótipos de feijoeiro com possíveis tolerância diferenciada a salinidade.

\section{MATERIAL E MÉTODOS}

O trabalho foi realizado em bandejas de polietileno com capacidade de 15 litros em casa de vegetação no Centro de Ciências Agrárias da Universidade Federal do Espírito Santo com coordenadas geográficas de $20^{\circ} 45^{\prime} \mathrm{S}, 41^{\circ} 29^{\prime} \mathrm{W}$ e altitude de $150 \mathrm{~m}$.

A seleção dos genótipos de feijoeiro com tolerância diferenciada à salinidade foi feita em delineamento inteiramente casualizado utilizando 30 genótipos de feijoeiro cultivados em substrato com quatro níveis de salinidade $(2,5 ; 5,0 ; 7,5$ e $10,0 \mathrm{dS}$ $\mathrm{m}^{-1}$ ) e, uma testemunha (substrato não salino) com seis repetições.

O solo utilizado no preenchimento das bandejas foi classificado como Argissolo Vermelho Escuro existente na área experimental do Centro de Ciências Agrárias da Universidade Federal do Espírito Santo. Após a homogeneização, a acidez foi corrigida, com a aplicação de calcário dolomítico, de acordo com a recomendação da Comissão de Fertilidade do Solo do Estado do Espírito Santo.

Cada camada de cinco centímetros de solo, colocada na bandeja, era homogeneizada com a procedente, até atingir a superfície. Todos os vasos receberam a mesma massa de solo, que foi colocada em igual volume de 15 litros. Cada bandeja era provida de drenagem de fundo ligada a um dispositivo para a coleta do efluente, de forma que o excesso de água aplicada era coletado.

Depois de montado o experimento, o solo foi 
salinizado, de forma casualizada, com aplicação de água salina com condutividade elétrica correspondentes a 2,$50 ; 5,00 ; 7,50$ e $10,00 \mathrm{dS} \mathrm{m}^{-1}$. A água salina utilizada na salinização do solo era provida da rede de abastecimento interno do Centro de Ciências Agrárias da UFES, sendo armazenada em reservatórios com capacidade de 60 litros. Neste local, a solução era preparada mediante a adição de $\mathrm{NaCl}$ e $\mathrm{CaCl}_{2}$ em quantidades necessárias para se obter uma condutividade elétrica para cada tratamento descrito anteriormente. Nessas condições obtinha-se uma relação iônica em peso equivalente de $3 \mathrm{Na}: 2 \mathrm{Ca}$., relação esta predominante nas águas salinas utilizadas na irrigação do Nordeste, conforme citado por Medeiros (1992).

A água salina foi aplicada nas bandejas contendo solo até o sistema atingir o equilíbrio. Ou seja, a quantidade de sais aplicada era a mesma coletada nos recipientes destinados a armazenar o efluente em excesso. $\mathrm{O}$ equilíbrio foi determinado com medições da condutividade elétrica do afluente e efluente.

A caracterização química e físico-hídrica do substrato (Quadro 1) foi feita no laboratório de Física e Fertilidade de Solo do Departamento Produção Vegetal da Universidade Federal do Espírito Santo. As análises químicas constituíram-se na determinação dos teores de $\mathrm{P}$ disponível, $\mathrm{K}, \mathrm{Ca}$, $\mathrm{Mg}, \mathrm{Na}, \mathrm{Al}$ trocável, $\mathrm{H}+\mathrm{Al}$, bem como a saturação de bases, CTC efetiva e $\mathrm{pH}$. Na análise física dos solos foram efetuadas as determinações de: areia, silte e argila (EMBRAPA, 1997).

Os dados de umidade relativa do ar e radiação solar incidente e temperatura, (Figura 1) foram coletados numa estação meteorológica, localizada dentro da casa de vegetação.

Dos genótipos de feijoeiro utilizados no experimento, alguns foram resgatados em pequenas comunidades de agricultores familiares da Região Sul do Estado do Espírito Santo, entre os quais foram Macuquinho, Amarelinho, Terrinha I, Fortuna, Terrinha II, Mamona, Amendoim vermelho, Mulatinho, Campinho, Bate-estrada, Enxofre, Caeté-pé-curto, Vagem riscada, Rosinha, Paina, Morgado, Macuquinho Verdadeiro e Uirapuru.

Quadro 1. Valores médios das características físico-químicas do substrato utilizado no preenchimento das bandejas após a salinização com água salina nas diferentes concentrações

\begin{tabular}{lclc}
\hline \multicolumn{1}{c}{ Características } & Valor & \multicolumn{1}{c}{ Características } & Valor \\
\hline Areia $(\%)$ & 0,26 & CTC total $\left(\mathrm{cmol}_{\mathrm{c}} \mathrm{dm}^{-3}\right)$ & 8,42 \\
Silte $(\%)$ & 0,34 & CTC efetiva $\left(\mathrm{cmol}_{\mathrm{c}} \mathrm{dm}^{-3}\right)$ & 7,67 \\
Argila $(\%)$ & 0,40 & Saturação por bases $(\%)$ & 89,70 \\
pH & 5,20 & Porcentagem de potássio trocável $(\%)$ & 0,99 \\
Fósforo $\left(\mathrm{mg} \mathrm{dm}^{-3}\right)$ & 4,83 & Porcentagem de cálcio trocável $(\%)$ & 47,07 \\
Potássio $\left(\mathrm{mg} \mathrm{dm}^{-3}\right)$ & 30,00 & Porcentagem de magnésio trocável $(\%)$ & 12,10 \\
Cálcio $\left(\mathrm{cmol}_{\mathrm{c}} \mathrm{dm}^{-3}\right)$ & 4,02 & Porcentagem de sódio trocável $(\%)$ & 29,55 \\
Magnésio $\left(\mathrm{cmol}_{\mathrm{c}} \mathrm{dm}^{-3}\right)$ & 0,83 & Relação cálcio/magnésio & 4,32 \\
Sódio $\left(\mathrm{mg} \mathrm{dm}^{-3}\right)$ & 592,17 & Salinidade do solo $\left(\mathrm{dS} \mathrm{m}^{-1}\right)$ & 5,96 \\
Alumínio $\left(\mathrm{cmol}_{\mathrm{c}} \mathrm{dm}^{-3}\right)$ & 0,00 & Razão de adsorção de sódio $\left(\mathrm{cmol}_{\mathrm{c}} \mathrm{dm}^{-3}\right)^{0,5}$ & 1,54 \\
$\mathrm{H}+\mathrm{Al}\left(\mathrm{cmol}_{c} \mathrm{dm}^{-3}\right)$ & 0,77 & Soma de bases $\left(\mathrm{cmol}_{c} \mathrm{dm}^{-3}\right)$ & 7,67 \\
\hline
\end{tabular}
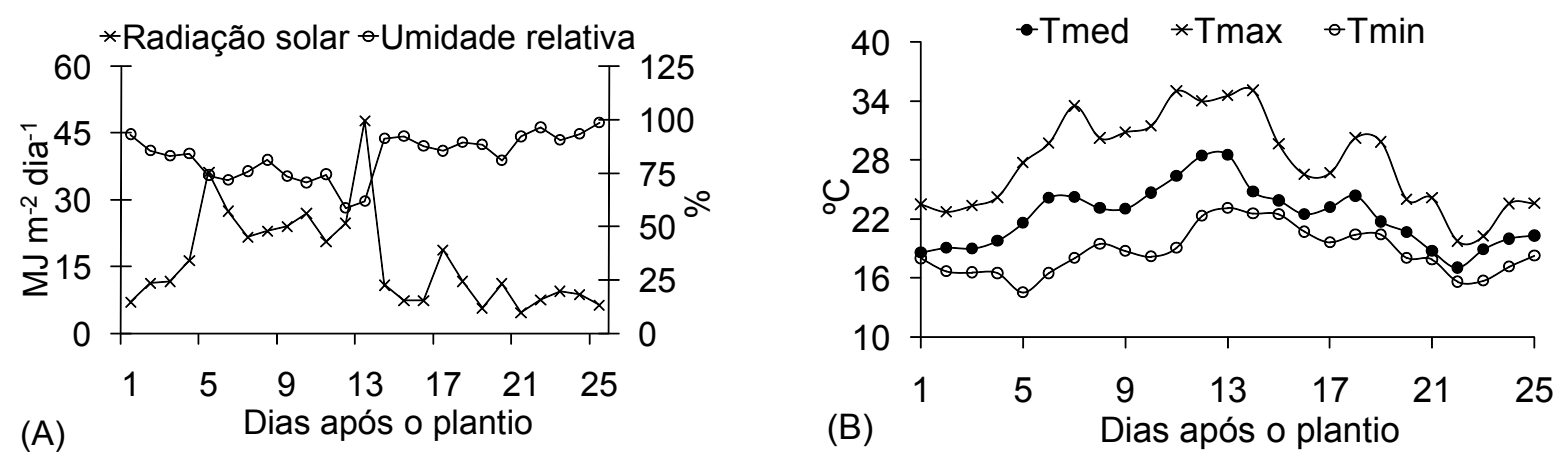

Figura 1. Radiação solar e umidade relativa média (A) e temperaturas máxima, mínima e média (B), obtidas dentro da casa de vegetação durante o período experimental. 
Outros foram obtidos do banco de germoplasma de genótipos comerciais da instituição dentre os quais foram IAPAR 81, Batt 477, Carioca, Monte Alegre, Rio Doce, Baetão, Imperial, Santa Maria, Levanta Hipoteca, Vermelho, Serrano e EL 22.

Antes do plantio, todos os tratamentos receberam adubação química de plantio calculada em função da disponibilidade de nutrientes presentes nos solos e na exigência nutricional da cultura, conforme estabelecido pela Comissão de Fertilidade do Solo do Estado do Espírito Santo.

As sementes foram postas para germinar em recipientes do tipo "gerbox", forrados com papel mata-borrão e umedecidos em água destilada. Aos cinco dias após a germinação, as plântulas foram transferidas para as bandejas de polietileno com solo salinizado. Em cada bandeja foram colocadas três plântulas de cada cultivar, ficando o sistema radicular imerso no substrato salino conforme cada tratamento, sendo que a coleta dos materiais foi feita aos 25 dias após transplantio para as bandejas.

Após a coleta dos materiais, foi feita uma análise do crescimento determinando a área foliar total (AFT); as taxas de crescimento absoluto (TCA) e relativo (TCR), a razão de área foliar (RAF), matéria seca total (MST), da parte aérea (MSPA) e das raízes (MSR) e a relação parte aérea/raíz (RPAR) conforme descrito por BENINCASA (2003). A determinação da matéria seca inicial foi realizada por meio de estimativa, a partir do peso da matéria fresca de cada plântula e do teor médio de umidade das mesmas, no início dos tratamentos salinos.

As taxas de crescimento absoluto (TCA), crescimento relativo (TCR), e assimilação líquida (TAL), e a razão de área foliar (RAF), foram calculadas empregando as equações:

$\mathrm{TCA}=(\mathrm{MSf}-\mathrm{MSi}) / \mathrm{t}\left(\mathrm{g} \mathrm{dia}^{-1}\right)$

$\mathrm{TCR}=(\operatorname{Ln}$ MSf - Ln Msi $\left.) / \mathrm{tg} \mathrm{g}^{-1} \mathrm{dia}^{-1}\right)$

$\mathrm{RAF}=\mathrm{AF} / \mathrm{MSf}\left(\mathrm{cm}^{2} \mathrm{~g}\right)$

$\mathrm{RPAR}=\mathrm{MSPA} / \mathrm{MSR}$

Em que MSi é matéria seca total inicial; MSf é a matéria seca total final e t é o intervalo de tempo entre as amostragens (dias), AF é a área foliar, MSPA é a matéria seca da parte aérea e MSR é a matéria seca das raízes..

As áreas foliares inicial (AFi) e final (AFf) foram determinadas em amostras na forma de discos de área conhecida. A área foliar é igual à relação entre o peso total das folhas secas pelo peso dos discos secos multiplicada pela área dos discos $\left(\mathrm{cm}^{2}\right)$.

Depois de tabulados, os dados foram analisados por meio de análise de variância, teste de média e regressão. Os modelos foram escolhidos baseados na significância dos coeficientes de regressão, utilizando o teste " $t$ " adotando-se $\alpha$ de até $5 \%$, no coeficiente de determinação $\left(\mathrm{r}^{2}\right)$ e no fenômeno em estudo.

\section{RESULTADOS E DISCUSSÃO}

A análise estatística dos resultados (Quadro 2) demonstrou que a interação Genótipo X Salinidade não foi significativa para nenhuma característica avaliada, por outro lado a análise independente do fator Genótipo afetou diretamente a MSPA,

Quadro 2. Resumo da análise de variância das características avaliadas do experimento com os genótipos de feijoeiro cultivados em substrato salino

\begin{tabular}{cccccc}
\hline FATOR & GL & MST & MSRA & MSPA & AFT \\
\hline GENOTIPOS & 29 & $0,186^{\text {ns }}$ & $0,129^{\text {ns }}$ & $0,041^{* *}$ & $5902,28^{* *}$ \\
SALINIDADE & 4 & $0,596^{* *}$ & $0,313^{*}$ & $0,266^{* *}$ & $39116,81^{* *}$ \\
GEN*SAL & 116 & $0,147^{\text {ns }}$ & $0,121^{\text {ns }}$ & $0,012^{\text {ns }}$ & $2066,61^{\text {ns }}$ \\
RESIDUO & 718 & 0,161 & 0,127 & 0,017 & 2178,16 \\
\hline CV $(\%)$ & - & 91,98 & 134,47 & 82,29 & 80,89 \\
\hline FATOR & GL & RPAR & TCA & TCR & RAF \\
\hline GENOTIPOS & 29 & $3,026^{\text {ns }}$ & $0,279 \times 10-3^{\text {ns }}$ & $0,266 \times 10-2^{* *}$ & $22219,52^{* *}$ \\
\hline SALINIDADE & 4 & $15,093^{* *}$ & $0,332 \times 10-3^{* *}$ & $0,106 \times 10-1^{* *}$ & $113364,20^{* *}$ \\
\hline GEN*SAL & 116 & $1,428^{\text {ns }}$ & $0,209 \times 10-3^{\text {ns }}$ & $0,110 \times 10-3^{\text {ns }}$ & $6936,89^{\text {ns }}$ \\
\hline RESIDUO & 718 & 2,336 & $0,221 \times 10-3^{\text {ns }}$ & $0,924 \times 10-3$ & 9748,27 \\
\hline CV $(\%)$ & - & 117,60 & 93,19 & 18,25 & 63,28 \\
\hline
\end{tabular}

GEN*SAL - Interação Genótipo x Salinidade; ns - Não significativo; *, ** - significativos a 5 e $1 \%$, respectivamente. 
AFT, TCR e RAF e o aumento dos níveis de Salinidade afetou significativamente o crescimento e o desenvolvimento dos genótipos estudados influenciando diretamente todas as características avaliadas.

$\mathrm{Na}$ Figura 2, estão apresentados respostas de todas as características avaliadas em função do aumento da salinidade do solo.

De forma geral, a MST e a MSRA dos genótipos de feijoeiro, Figuras 1A e 1B respectivamente, apresentaram um modelo do tipo quadrático. Os valores destas duas variáveis diminuíram até $5,00 \mathrm{dS} \mathrm{m}^{-1}$ a partir desta condutividade elétrica houve um acréscimo dos valores de MST e MSRA com o aumento dos níveis de salinidade do solo. O incremento nos valores destas varáveis após $5,00 \mathrm{dS} \mathrm{m}^{-1}$ foi devido ao maior investimento dos genótipos em raiz.

Dantas et al. (2002) também constataram em 50 genótipos de feijão caupi reduções, estatisticamente significativas, na produção de matéria seca, em função do aumento da salinidade do solo, explicadas por modelos lineares ou quadráticos. Durante o estádio inicial de crescimento Gonzales et al. (2000) estudando o efeito de níveis crescentes de condutividade elétrica na solução nutritiva $\left(0,3,6,9,12\right.$ e $\left.15 \mathrm{dS} \mathrm{m}^{-1}\right)$ sobre o crescimento de 11 cultivares de feijão caupi, constataram que os índices de crescimento (altura, comprimento radicular e peso de matéria seca das plântulas) decresceram a medida em que a condutividade elétrica na solução aumentou, tendo as cultivares diferido quanto ao grau de tolerância ao estresse salino.

A MSPA e a AFT (Figuras 1C e 1D, respectivamente) diminuíram com o aumento dos níveis de salinidade no substrato onde as plantas foram cultivadas. Com o aumento dos níveis de salinidade do solo, possivelmente ocorreu a diminuição do potencial osmótico da solução do solo ocasionado assim o decréscimo do potencial matricial da água no solo. Desta maneira, poderia ter ocorrido uma resistência das plantas para absorver a água no solo. Esse aumento de pressão osmótica pode atingir valores em que as plantas não terão forças de sucção suficiente para superar esse potencial, e conseqüentemente, não conseguirão absorver água, mesmo em um solo aparentemente úmido, fenômeno conhecido como seca fisiológica, refletindo diretamente na expansão celular, diminuindo assim a AFT e conseqüentemente no acumulo de matéria seca da parte aérea das plantas.

Semelhantemente, Bayuleo-Jiménez et al. (2003) verificaram a diminuição da produção de matéria seca total, das raízes e da parte aérea além da relação parte aérea/raiz e da área foliar total em seis genótipos de feijoeiro cultivados em solução nutritiva com níveis crescentes de salinidade, dentro de casa de vegetação. Silveira et al. (1999) também constataram que o tratamento de plantas de feijão caupi com $100 \mathrm{mM}$ de $\mathrm{NaCl}$ na solução nutritiva ocasionou redução no acúmulo de matéria seca da parte aérea e na relação parte aérea/raiz.

Observando a resposta da RPAR e a RAF (Figuras 1E e 1H, respectivamente) nota-se que ambas as características apresentaram resposta quadrática, aumentando seus valores até próximo a $3 \mathrm{dS} \mathrm{m}^{-1}$. Em ambas, a partir deste valor ocorreu diminuição. Em relação à RPAR, podem-se considerar dois aspectos distintos: com o aumento inicial dos níveis de salinidade do solo, ocorre um maior efeito na parte aérea das plantas de feijoeiro até aproximadamente o nível de salinidade próximo a $3 \mathrm{dS} \mathrm{m}^{-1}$, a partir do qual o efeito da salinidade passa a ser maior nas raízes, reduzindo o acumulo de massa das mesmas. O mesmo raciocínio pode ser aplicado a RAF, pois com o aumento dos níveis de salinidade do solo ocorre um maior efeito na área foliar e posteriormente, com a queda dos valores da RAF, o efeito da salinidade torna-se mais evidente no acúmulo de matéria seca. $\mathrm{O}$ aumento dos níveis de salinidade diminuiu a velocidade e o impulso do crescimento das plantas de feijoeiro, representado pela TCA e TCR, Figuras $1 \mathrm{~F}$ e $1 \mathrm{G}$, respectivamente. Contudo esse efeito foi menos pronunciado acima dos níveis de salinidade de 7,5 $\mathrm{dS} \mathrm{m}^{-1}$. Desta forma, semelhantemente ao verificado para a razão parte aérea/raiz e RAF a TCA e a TCR foram duas variáveis importantes na diferenciação das características de tolerância ou sensibilidade ao estresse salino nos cultivares estudados.

No Quadro 3, estão apresentadas as médias da MSPA, AFT, TCR e RAF dos genótipos avaliados.

Observa-se no Quadro 3 que os genótipos Serrano, Vagemriscada, EnxofreeCarioca apresentarammaiores valores de MSPA em relação aos demais genótipos. Por outro lado, os cultivares Santa Maria, Rio doce, Monte alegre, Fortuna e Amarelinho, apresentaram as maiores reduções dos valores da MSPA quando cultivados sob níveis crescentes de salinidade do solo.

Os processos de crescimento são particularmente sensíveis ao efeito dos sais, de forma que a taxa 

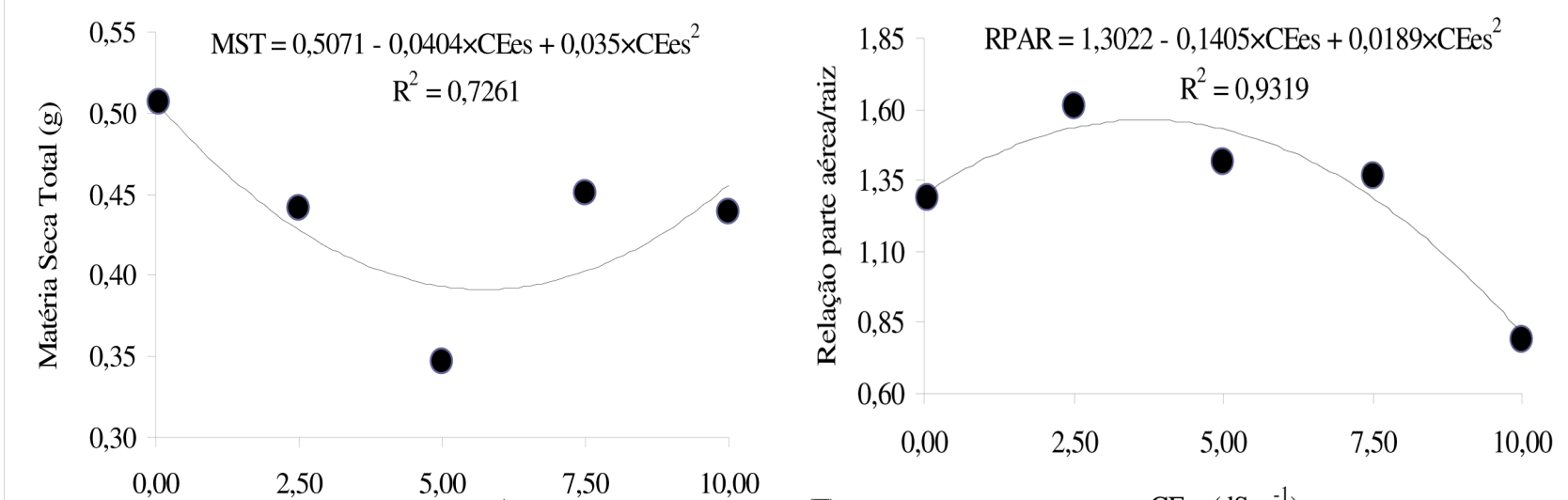

(A)

CEes $\left(\mathrm{dS} \mathrm{m} \mathrm{m}^{-1}\right)$

(E)

CEes $\left(\mathrm{dS} \mathrm{m}^{-1}\right)$

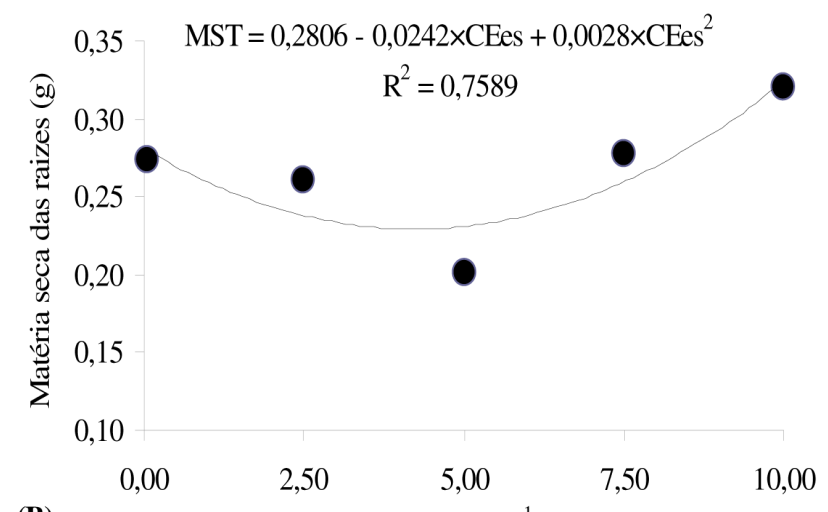

(B) $\quad \mathrm{CEes}\left(\mathrm{dS} \mathrm{m}^{-1}\right)$
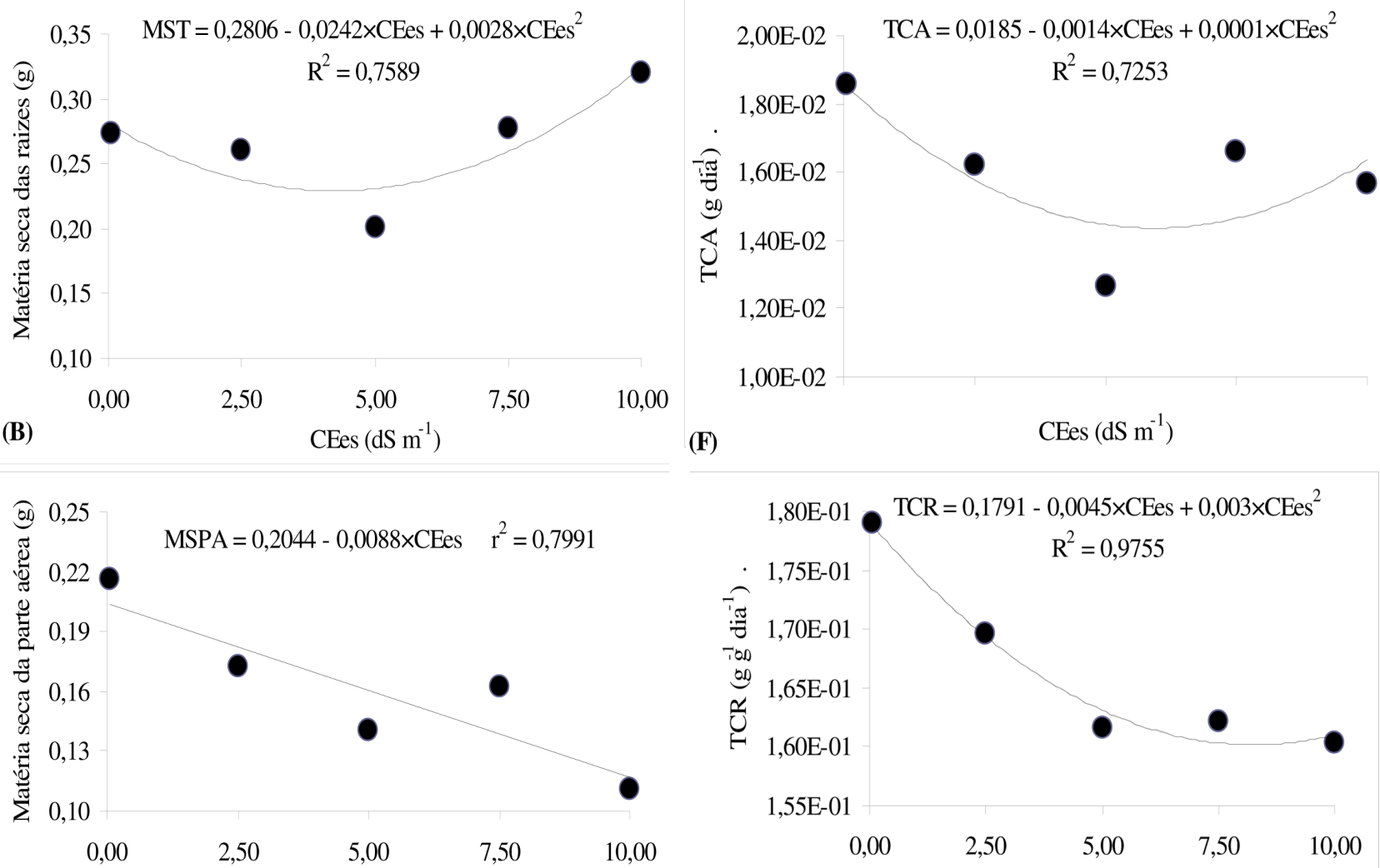

(C)

CEes $\left(\mathrm{dS} \mathrm{m} \mathrm{m}^{-1}\right)$

(G)

CEes $\left(\mathrm{dS} \mathrm{m}^{-1}\right)$
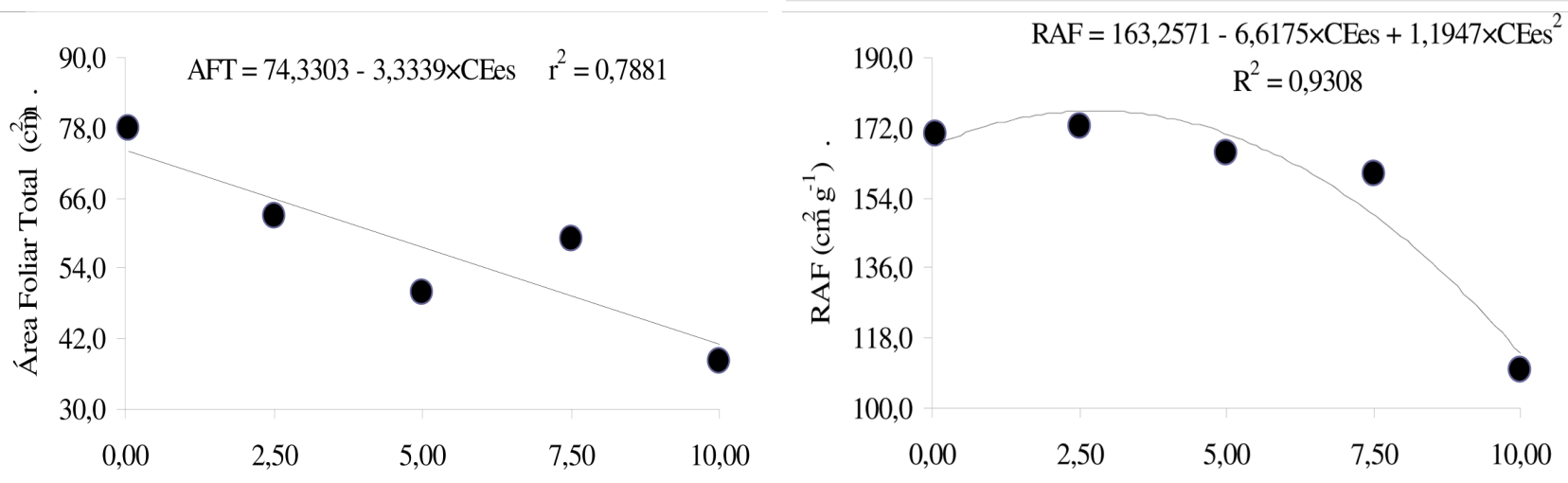

(D)

$\operatorname{CEes}\left(\mathrm{dS} \mathrm{m} \mathrm{m}^{-1}\right)$

(H)

CEes $\left(\mathrm{dS} \mathrm{m}{ }^{-1}\right)$

Figura 2. Matéria seca total (A), das raízes (B), da parte aérea (C), área foliar total (D), relação parte aérea raiz (E), taxas de crescimento absoluto $(\mathrm{F})$ e relativo $(\mathrm{G})$ e razão de área foliar $(\mathrm{H})$ dos genótipos de feijoeiro cultivados em substrato com níveis crescentes de salinidade. 
de crescimento e a produção de biomassa são bons critérios para avaliação do grau de estresse, bem como a capacidade da planta em tolerar o estresse salino (LARCHER, 2000). Nesse sentido, a redução da biomassa pelos genótipos de feijoeiro está relacionado com o teor relativo de água nas folhas, o qual pode permanecer quase que inalterado em decorrência do fechamento dos estômatos (COSTA, 1999). Este mecanismo, que previne as perdas de água pela redução da transpiração e, ao mesmo tempo, mantém o teor relativo de água a nível similar ao das plantas sob condições não salinas (FERRARIO et al., 1998; FOYER et al., 1998). A interrupção do suprimento de $\mathrm{CO}_{2}$ para a fotossíntese, causada pelo fechamento estomático, diminui a produção de biomassa. A salinidade também causa decréscimo na atividade da enzima nitrato redutase foliar e na absorção de nitrato (COSTA, 1999) limitando, também, a produção de matéria seca da parte aérea das plantas de feijoeiro.

Observando o Quadro 3, nota-se que o genótipo Serrano apresentou valor de AFT e RAF superior aos demais genótipos. Por outro lado os genótipos Terrinha e Amarelinho apresentaram menores valores de área foliar e o genótipo Uirapuru apresentou menor valor da RAF, demonstrando assim, menor tolerância ao estresse salino quando cultivados sob níveis crescentes de salinidade. $\mathrm{O}$ estresse salino induz uma redução progressiva do crescimento das plantas o que pode ser causado pela redução do potencial osmótico e/ou acumulação excessiva de íons no protoplasma, podendo induzir à toxicidade iônica, desequilíbrio nutricional ou ambos. Tendo em vista a diminuição do tamanho das plantas e o tamanho das folhas, a planta reduz a superfície de transpiração e a área exposta para

Quadro 3. Valores médios ${ }^{1}$ da matéria seca da parte aérea (MSPA), área foliar total (AFT), taxa de crescimento relativo (TCR) e da razão de área foliar (RAF) dos genótipos de feijoeiro cultivados em substrato salino

\begin{tabular}{lcccc}
\hline GENÓTIPO & MSPA $(\mathrm{g})$ & $\mathrm{AFT}\left(\mathrm{cm}^{2}\right)$ & $\mathrm{TCR}\left(\mathrm{g} \mathrm{g}^{-1} \mathrm{dia}^{-1}\right)$ & $\mathrm{RAF}\left(\mathrm{cm}^{2} \mathrm{~g}^{-1}\right)$ \\
\hline Macuquinho & $0,146 \mathrm{c}$ & $53,400 \mathrm{f}$ & $0,170 \mathrm{~b}$ & $147,255 \mathrm{f}$ \\
Amarelinho & $0,115 \mathrm{~d}$ & $38,272 \mathrm{~h}$ & $0,137 \mathrm{c}$ & $133,299 \mathrm{f}$ \\
Terrinha I & $0,131 \mathrm{c}$ & $37,211 \mathrm{~h}$ & $0,147 \mathrm{~d}$ & $121,475 \mathrm{~g}$ \\
Fortuna & $0,118 \mathrm{~d}$ & $40,171 \mathrm{~g}$ & $0,154 \mathrm{c}$ & $144,196 \mathrm{f}$ \\
IAPAR 81 & $0,132 \mathrm{c}$ & $48,451 \mathrm{f}$ & $0,166 \mathrm{~b}$ & $140,472 \mathrm{f}$ \\
Batt 477 & $0,156 \mathrm{c}$ & $61,273 \mathrm{f}$ & $0,166 \mathrm{~b}$ & $165,541 \mathrm{f}$ \\
Terrinha II & $0,178 \mathrm{~b}$ & $68,293 \mathrm{~d}$ & $0,164 \mathrm{c}$ & $175,170 \mathrm{~d}$ \\
Carioca & $0,216 \mathrm{a}$ & $80,091 \mathrm{c}$ & $0,176 \mathrm{a}$ & $185,164 \mathrm{c}$ \\
Monte Alegre & $0,122 \mathrm{~d}$ & $40,883 \mathrm{~g}$ & $0,165 \mathrm{c}$ & $142,067 \mathrm{f}$ \\
Rio Doce & $0,123 \mathrm{~d}$ & $43,984 \mathrm{~g}$ & $0,168 \mathrm{~b}$ & $113,129 \mathrm{~g}$ \\
Baetão & $0,189 \mathrm{~b}$ & $70,398 \mathrm{~d}$ & $0,176 \mathrm{a}$ & $159,424 \mathrm{f}$ \\
Mamona & $0,154 \mathrm{c}$ & $61,491 \mathrm{f}$ & $0,160 \mathrm{c}$ & $182,441 \mathrm{c}$ \\
Amendoim vermelho & $0,144 \mathrm{c}$ & $59,732 \mathrm{f}$ & $0,163 \mathrm{c}$ & $143,508 \mathrm{f}$ \\
Mulatinho & $0,164 \mathrm{c}$ & $55,018 \mathrm{f}$ & $0,167 \mathrm{~b}$ & $167,865 \mathrm{~d}$ \\
Campinho & $0,192 \mathrm{~b}$ & $70,015 \mathrm{~d}$ & $0,167 \mathrm{~b}$ & $223,872 \mathrm{~b}$ \\
Bate-estrada & $0,145 \mathrm{c}$ & $51,634 \mathrm{f}$ & $0,176 \mathrm{a}$ & $127,414 \mathrm{~g}$ \\
Enxofre & $0,209 \mathrm{a}$ & $72,147 \mathrm{~d}$ & $0,175 \mathrm{a}$ & $165,501 \mathrm{f}$ \\
Imperial & $0,122 \mathrm{~d}$ & $41,796 \mathrm{~g}$ & $0,171 \mathrm{a}$ & $112,839 \mathrm{~g}$ \\
Santa Maria & $0,117 \mathrm{~d}$ & $41,119 \mathrm{~g}$ & $0,157 \mathrm{c}$ & $160,728 \mathrm{f}$ \\
Caeté-pé-curto & $0,135 \mathrm{c}$ & $48,931 \mathrm{f}$ & $0,163 \mathrm{c}$ & $147,911 \mathrm{f}$ \\
Vagem riscada & $0,248 \mathrm{a}$ & $85,871 \mathrm{~b}$ & $0,179 \mathrm{a}$ & $198,928 \mathrm{~b}$ \\
Levanta Hipoteca & $0,149 \mathrm{c}$ & $54,801 \mathrm{f}$ & $0,167 \mathrm{~b}$ & $159,645 \mathrm{f}$ \\
Rosinha & $0,192 \mathrm{~b}$ & $67,441 \mathrm{~d}$ & $0,171 \mathrm{a}$ & $179,388 \mathrm{~d}$ \\
Paina & $0,179 \mathrm{~b}$ & $63,430 \mathrm{e}$ & $0,168 \mathrm{~b}$ & $173,932 \mathrm{~d}$ \\
Vermelho & $0,173 \mathrm{~b}$ & $62,321 \mathrm{f}$ & $0,160 \mathrm{c}$ & $155,530 \mathrm{f}$ \\
Morgado & $0,151 \mathrm{c}$ & $53,613 \mathrm{f}$ & $0,164 \mathrm{c}$ & $166,389 \mathrm{e}$ \\
Macuquinho Verdadeiro & $0,156 \mathrm{c}$ & $55,062 \mathrm{f}$ & $0,171 \mathrm{a}$ & $130,930 \mathrm{f}$ \\
Serrano & $0,258 \mathrm{a}$ & $92,282 \mathrm{a}$ & $0,184 \mathrm{a}$ & $289,014 \mathrm{a}$ \\
Uirapuru & $0,132 \mathrm{c}$ & $47,017 \mathrm{f}$ & $0,175 \mathrm{a}$ & $98,133 \mathrm{~h}$ \\
EL 22 & $0,173 \mathrm{~b}$ & $64,103 \mathrm{e}$ & $0,167 \mathrm{~b}$ & $161,336 \mathrm{f}$ \\
\hline
\end{tabular}

${ }^{1}$ Médias seguidas pela mesma letra na coluna não diferem entre si, pelo teste de Tuckey a $5 \%$ probabilidade 
captar radiação. Com a planta transpirando menos, possivelmente irá absorver menos nutrientes via solução do solo além de suceder menos troca de $\mathrm{CO}_{2}$ com o meio ambiente e reduzindo assim o seu potencial fotossintético e conseqüentemente a produtividade.

Uma das explicações mais aceitas para a inibição do crescimento pelo estresse salino é o desvio de energia do crescimento para a manutenção, isto é, a redução na matéria seca das plantas pode refletir o custo metabólico de energia, associado à adaptação a salinidade e redução no ganho de carbono (RICHARDSON \& MCCREE, 1985). Pode-se incluir também a regulação do transporte e distribuição iônica em vários órgãos e dentro das células, a síntese de solutos orgânicos para a osmorregulação e, ou proteção de macromoléculas, e a manutenção da integridade das membranas. Dessa forma, de acordo com os resultados apresentados na Quadro 3 a menor redução no crescimento dos genótipos mais tolerantes pode estar associada, entre outros fatores, a um menor custo energético para osmorregulação, o qual pode ser conseguido por meio da acumulação e da compartimentação de solutos inorgânicos no vacúolo e solutos orgânicos no citoplasma (TAL, 1985).Este fenômeno pode estar associado a um ajustamento osmótico mais rápido e a uma perda de turgor mais lenta das raízes, quando comparadas com a parte aérea. Conseqüentemente, o crescimento radicular pode ser menos sensível que o crescimento da parte aérea a uma redução no potencial osmótico (SHALHEVET et al., 1995).

A redução da AFT dos genótipos de feijoeiro mais sensíveis (Quadro 3) deve-se ao estresse osmótico seguido do estresse hídrico, os quais são decorrentes do estresse hídrico e salino, tendo como efeito imediato à diminuição do conteúdo de água da planta, proveniente da diminuição do potencial matricial e osmótico, devido à diminuição do conteúdo de água no solo e da elevada concentração iônica, ocasionada principalmente pelo sódio e cloro. O decréscimo do volume celular resulta em uma menor pressão de turgor e na subseqüente concentração de solutos nas células tornando a membrana celular mais espessa e comprimida. Por ser a redução de turgor o efeito biofísico significante mais precoce do estresse hídrico, as atividades dependentes do turgor, como a expansão foliar e o alongamento de raízes, são mais sensíveis ao déficit hídrico (TAIZ \& ZEIGER, 2004).

\section{CONCLUSÃO}

A análise dos dados e a interpretação dos resultados obtidos nas condições específicas do presente trabalho permitem concluir que:

- A salinidade afetou significativamente o crescimento e o desenvolvimento dos genótipos estudados;

- O genótipo Serrano apresentou em relação aos demais genótipos, maiores de MSPA, AFT, TCR e RAF demonstrando maior tolerância ao estresse salino;

- Os genótipos Monte Alegre, Fortuna e Amarelinho demonstraram menor tolerância ao estresse salino.

\section{AGRADECIMENTOS}

Os autores agradecem ao $\mathrm{CNPq}$ pelo financiamento da pesquisa e pela concessão das bolsas de Pós-doutorado Junior e Iniciação científica.

\section{REFERÊNCIAS BIBLIOGRÁFICAS}

AZEVEDO NETO, A.D. Estudo do crescimento e distribuição de nutrientes em plantas de milho submetidas ao estresse salino. 1997. Dissertação (Mestrado em Fisiologia Vegetal). 134p. Universidade Federal Rural de Pernambuco, Recife, 1997.

BAYUELO-JIMENEZ, J.S.; DEBOUCK, D.G., LYNCH, J.P. Growth, gas exchange, water relations, and in composition of Phaseolus species grown under saline conditions. Field Crops Research. Madison, v.80, p.207-222, 2003.

BENINCASA, M.M.P. Análise de crescimento de plantas (noções básicas). 2. ed. Jaboticabal: FUNEP, 2003. 41p.

COSTA, R.C.L. Assimilação de nitrogênio e ajustamento osmótico em plantas noduladas de feijão-de-corda, submetidas ao estresse hídrico. 1999. 187p. Tese (Doutorado em Fitotecnia). Universidade Federal do Ceará, Fortaleza, 1999.

CRAMER, G.R.; ALBERICO, G.J.; SCHMIDT, C. Salt tolerance is not associated with the sodium 
accumulation of two maize hybrids. Australian Journal of Plant Physiologic. Melbourne, v.21, p.675-692, 1994.

DANTAS, J.P.; MARINHO, F.J.L.; FERREIRA, M.M.M.; AMORIM, M.S.N.; ANDRADE, S.O.; SALES, A.L. Avaliação de genótipos de caupi sob salinidade. Revista Brasileira de Engenharia Agrícola e Ambiental, Campina Grande, v.6, n.3, p.425-430, 2002.

EMBRAPA. Manual de métodos de análise de solo. 2. ed. Rio de Janeiro: CNPS, 1997. 212p.

FAGERIA, N.K. Solos tropicais e aspectos fisiológicos das culturas. Brasília: EMBRAPA/ DPU, 1989. 425p.

FERRARIO, S.; VALADIER, M.; FOYER, C.H. Over-expression of nitrate reductase in tobaco delays drought-induced decreases in nitrate reductase activity and mRNA. Plant Physiology, Bethesda, v.117, n.2, p.293-302, 1998.

FOYER, C.H.; VALADIER, M.; MIGGE, A.; BECKER, T.W. Drough tinduced effects on nitrate reductase activity and mRNA and on coordination of nitrogen and carbon in maize leaves. Plant Physiology, Bethesda, v.117, n.3, p.283-292, 1998.

GONZALES, L.M.; ZAMORA, A.; CESPEDES, N. Salt tolerance of cultivars of Vigna unguiculata (L.) Walp during the initial growth stages of plants. Alimentaria, Madri, v.37, n.314, p.105-108, 2000.

LARCHER, W. Ecofisiologia Vegetal. São Carlos:
RiMa Artes e Textos, 2000. 531p.

MEDEIROS, J.F. Qualidade da água de irrigação e evolução da salinidade nas propriedades assistidas pelo gat, nos estados do RN, PB e CE. 1992. Dissertação (Mestrado em Engenharia Agrícola) - Universidade Federal da Paraíba, Campina Grande, 1992.

MUNNS, R.; TERMAAT, A. Whole plant responses to salinity. Australian Journal of Plant Physiology, Melbourne, v.13, p.143-160, 1986.

RICHARDSON, S.G.; McCREE, K.J. Carbon balance and water relations of sorghum exposed to salt and water stress. Plant Physiology, Bethesda, v.79, p.1015-1020, 1985.

SILVEIRA, J.A.G.; CARDOSO, B.B.; MELO, A.R.B.; VIÉGAS, R.A. Salt-induced decrease in nitrate uptake and assimilation in cowpea plants. Revista Brasileira de Fisiologia Vegetal, Campinas, v.11, n.2, p.77-82, 1999.

SHALHEVET, J.; HUCK, M.G.; SCHROEDER, B.P. Root and shoot growth responses to salinity in maize and soybean. Agronomy Journal, Madison, v.87, p.512-516, 1995.

TAIZ, L., ZEIGER, E. Fisiologia Vegetal. 3. ed. Porto Alegre: Artmed, 2004. 719p.

TAL, M. Genetics of salt tolerance in higher plants: theoretical and practical considerations. Plant and Soil. Madison, v.89, p.199-226, 1985. 